\title{
OCORRÊNCIA DE BACTÉRIAS DO GÊNEROAzospirillum spp. ASSOCIADAS A GRAMÍNEAS FORRAGEIRAS NO SEMIÁRIDO NORDESTINO
}

\section{F. T. A. MOREIRA', D. R. SANTOS', G. H. SILVA', L. S. ALENCAR'}

'Laboratório de Análise de Solos e Água - Universidade Federal de Campina Grande tiberiopcz@gmail.com-santos@cstr.ufcg.edu.br-niohkr888@rocketmail.com -lyanne.florestal@hotmail.com

Artigo submetido em agosto/2012 e aceito em maio/2013

\section{RESUMO}

A fixação biológica de $\mathrm{N}_{2}$, associada às plantas forrageiras é importante no ciclo do nitrogênio, pois bactérias podem atender no suprimento do nutriente necessário às plantas. Amostras de raízes foram coletadas de três gramíneas: Andropogon, Capim Tanzânia e Capim Buffel. Para bactérias isoladas em meio seletivo procederam-se: Quantificação, caracterização fenotípicas, eposteriormente purificadas com hipoclorito de sódio e armazenadas em sacos plásticos. A densidade de bactérias foi influenciada pelos nichos radiculares e gramíneas forrageiras, sendo o capim Andropogon e Buffel que apresentaram maiores densidades de microorganismos.

PALAVRAS-CHAVE: Fixação Biológica de $\mathrm{N}_{2}$, Pastagem, Microorganismos.

\section{OCCURRENCE OF BACTERIA OF THE GENERA Azospirillumspp. ASSOCIATED GRASSY FORAGE IN THE SEMI-ARID OF THE NORTHEAST OF BRAZIL}

\begin{abstract}
The biological fixation of $\mathrm{N}_{2}$, associated to plant forage is an important stage in the cycle of the nitrogen, because bacteria can contribute in the part supply of necessary $\mathrm{N}$ to the plants. The samples of roots were collected of three grassy: Andropogon, Tanzania and Buffel. The isolated bacteria in selective way, they were
\end{abstract} characterization, and later purified with sodium hypochloride and stored it in plastic bags. The density of the bacteria was influenced by the root niches and grassy forage, being the grass Andropogon and Buffel that showed larger densities of microorganisms. 


\section{OCORRÊNCIA DE BACTÉRIAS DO GÊNERO Azospirillum spp. ASSOCIADAS A GRAMÍNEAS FORRAGEIRAS NO SEMIÁRIDO NORDESTINO}

\section{INTRODUÇÃO}

A degradação ambiental ocorrida nas últimas décadas gerou diversas alterações no meio ambiente. E devido a isso, as florestas tropicais vem sendo o alvo principal para a venda de madeira nobre e pela substituição por áreas de cultivo ou pastagens, o que vem comprometendo a fertilidade dos solos (Faria, 2002).

A perda da fertilidade do solo tem como principal causa o desaparecimento da matéria orgânica, causando problemas sérios na atividade biológica, retenção de água, no suprimento de enxofre, fósforo e principalmente de nitrogênio às plantas, e como consequência a produtividade do sistema (Franco et al., 1992).

Bactérias diazotróficas endofíticas são aquelas que fixam $\mathrm{N}_{2}$ atmosférico e colonizam o interior de tecidos vegetais sem causar sintomas de doenças. Dentre as mais estudadas destacam-se aquelas pertencentes aos gêneros Azosporilum, Herbaspirillum, Acetobacter, Burkholderia e Azoarcus. Bactérias do gênero Azosporillum são consideradas endofiticas facultativas (Baldani et al., 1997), pois além de colonizarem os hospedeiros podem sobreviver no solo na forma de cistos (Bashan \& Holguin, 1997). Apesar da especificidade com relação a seus hospedeiros ser baixa (Baldani et al., 1997), a associação dessas bactérias fixadoras de nitrogênio é mais frequente com gramíneas (Baldani et al., 1999).

Os microrganismos diazotróficos endofíticos do gênero Azospirillumspp. desempenham importante papel na reabilitação e sustentabilidade dos ecossistemas, uma vez que incorporam $\mathrm{N}$ por meio da fixação biológica em quantidade que podem variar de $25-50 \mathrm{~kg} \mathrm{ha}^{-1}$ ano $^{-1}$ de N e ainda produzem e liberam substâncias reguladoras de crescimento vegetal, como auxinas, giberelinas e citocininas, as quais contribuem para melhorar a nutrição mineral e utilização de água pelas plantas (Bazzicalupo \& Okon, 2000).

Atualmente há seis espécies descritas para o gênero Azospirillum: A.brasiliense; $A$. amazonense; $A$. lipoferum; $A$. halopraeferens; $A$. irekense; $A$. largomorbilis. Sendo duas as mais estudadas: $A$. brasiliense e $A$. lipoferum.E, ocorrem em grande abundância nas regiões tropicais em associações com gramíneas forrageiras como: Milho, trigo, arroz e sorgo.

No entanto, Baldani et al. (1999) relataram que a ocorrência e a atividade dessas bactérias no solo e na planta são fortemente influenciadas por estresses físicos (baixa umidade e alta temperatura), químicos (acidez e baixos teores de nutrientes) e biológicos (espécie vegetal não hospedeira), alguns dos quais são comuns na região semiárida, razão porque podem influenciar as populações destas bactérias.

Divido a diversidade de bactérias está diretamente relacionada com a espécie vegetal associada (Baldani et al., 1999), registram-se resultados bastante diversificados dessa associação com Azospirillumspp. em raízes e solo de outras gramíneas, como milho e sorgo, no Sudeste do Brasil ( $10^{6}$ a $10^{7}$ bactérias $\mathrm{g}^{-1}$ de solo) (Dobereiner, 1992), em raízes de pupunha e braquiária na Amazônia $\left(10^{5}\right.$ bactérias $\mathrm{g}^{-1}$ de solo) (Magalhães \& Dobereiner, 1984), em raízes desinfestadas 
superficialmente e na rizosfera de espécies de braquiárias em Goiás e Minas Gerais $\left(10^{3}\right.$ a $10^{7}$ bactérias $\mathrm{g}^{-1}$ ) (Reis Jr. et al., 2000).

A melhor compreensão da diversidade da microbiota no solo pode propiciar o desenvolvimento de estratégias, que permitam a otimização dos processos biológicos que, por sua vez, visem aumentar a sustentabilidade dos agrossistemas (Odum, 1988). Apesar dos métodos moleculares serem considerados essenciais para identificação destas bactérias (Kirchof et al., 1997).

As características morfológicas são também aplicáveis em estudos exploratórios da diversidade destas bactérias em diferentes ambientes (Melloni et al., 2004).

Embora as gramíneas sejam frequentemente plantadas ou semeadas em algumas áreas nobres na região semiárida do Nordeste, não há estudos sobre bactérias diazotróficas endofíticas em solos dessa região.

O objetivo do presente estudo foi avaliar a densidade e a diversidade fenotípica de bactérias diazotróficas endofíticas em dois nichos radiculares de três gramíneas forrageiras.

\section{MATERIAL E MÉTODOS}

As amostras das gramíneas escolhidas foram obtidas no campo de cultivo da coleção de forragem no Setor de Agrostologia do Centro de Saúde e Tecnologia Rural da Universidade Federal de Campina Grande, situado na mesoregião do Espinharas no Sertão Paraibano, tendo com coordenadas geográficas $07^{\circ} 04^{\prime} 32^{\prime \prime} \mathrm{S}$ de latitude e $37^{\circ} 16^{\prime} 26^{\prime \prime} \mathrm{W}$ de longitude. $\mathrm{O}$ solo é da área é predominantemente do tipo Neossolo (Embrapa, 1999).

Foram tomadas três espécies de gramíneas forrageiras com potencial para o cultivo em pastagens na região semiárida do Nordeste: Capim Andropogon (Andropogon gayanus), Capim Tanzânia (Panicum maximum) e Capim Buffel (Cenchrus ciliaris). As coletas foram feitas aleatoriamente, tomando-se três amostras de cada espécie forrageira.

As amostras das raízes das gramíneas foram coletadas na época das chuvas (JaneiroAbril), acondicionadas em sacos plásticos e prontamente transportadas ao laboratório de solos, sendo separadas em duas sub-amostras para a obtenção dos dois diferentes nichos radiculares.

Após a lavagem em água corrente, $10 \mathrm{~g}$ de amostras de raízes frescas foram cortadas em pedaços de cerca de $2,0 \mathrm{~cm}$ e desinfectadas com hipoclorito de sódio (2\%), e outras $10 \mathrm{~g}$ foram submetidas apenas à lavagem em água destilada,posteriormente, foram postas em $90 \mathrm{~mL}$ de solução salina diluída (30\%) usada como dispersante. Apenas as amostras das raízes que sofreram desinfecção superficial foram submetidas a maceragem com auxílio de almofariz.

Realizaram-se diluições sucessivas das amostras das raizes em solução salina diluída de $10^{-1}$ (10g de raiz fresca: $90 \mathrm{~mL}$ de solução salina) a $10^{-5}$, homogenizadas em vortex, antes da inoculação de 1,0 mL destas suspenções em frascos com $5 \mathrm{~mL}$ de meio de cultura semi-sólido (NFb) em triplicata por diluição, recomendado para Azospirillumspp (Döbereiner et al., 1995), com a seguinte composição: 5,0 g - Ácido málico; 0,5 g - $\mathrm{K}_{2} \mathrm{HPO}_{4} ; 0,2 \mathrm{~g}-\mathrm{MgSO} 4.7 \mathrm{H}_{2} \mathrm{O} ; 0,1 \mathrm{~g}-$ $\mathrm{NaCl} ; 0,02 \mathrm{~g}-\mathrm{CaCl}_{2} \cdot 2 \mathrm{H}_{2} \mathrm{O} ; 2 \mathrm{ml}$ solução de micronutrientes $\left(0,04 \mathrm{~g} \mathrm{CuSO}_{4} \cdot 5 \mathrm{H}_{2} \mathrm{O} ; 1,2 \mathrm{~g} \mathrm{ZnSO}_{4} .7 \mathrm{H}_{2} \mathrm{O}\right.$; 1,4 $\mathrm{g} \mathrm{H}_{3} \mathrm{BO}_{3} ; 1,0 \mathrm{~g} \mathrm{NaMoO}_{4} .2 \mathrm{H}_{2} \mathrm{O} ; 1,175 \mathrm{~g} \mathrm{MnSO}_{4} . \mathrm{H}_{2} \mathrm{O}$ ); $2 \mathrm{ml}$ de azul de bromotimol (solução 0,5\% em $\mathrm{KOH} \mathrm{0,2} \mathrm{N);} 4 \mathrm{ml}$ de Fe EDTA (solução 1,64 \%); $1,0 \mathrm{~mL}$ solução de vitamina (100 mg de biotina; $200 \mathrm{mg}$ piridoxol-HCl). 
Foi ajustado o pH para 6,5 com $\mathrm{KOH}$ e adicionado 1,8 g de Agar para meio semi-sólido; água q.s.p. $1000 \mathrm{~mL}$.

Estas culturas foram mantidas sob incubação por cinco dias a 28-30 ำ, avaliando-se posteriormente a presença $(+)$ ou ausência (-) do crescimento bacteriano identificado pela formação de película próximo a superfície no meio de cultura. Utilizou-se tabela de McCrady para a determinação do NMP (número mais provável) destas bactérias por gramas de amostra de raiz fresca.

Para obtenção dos isolados e avaliação da diversidade fenotípica, transferiram-se, com auxilio de alça de platina, uma porção de películas crescidas nas culturas utilizadas para avaliação semiquantitativa e contagem para os mesmos meios de cultura semi-sólido (NFb). As novas películas formadas foram repicadas, para este meio, agora, com consistência sólida (15 g t${ }^{-1}$ de agar e extrato de levedura).

Após cinco dias de incubação a 28-30 ำ, as colônias isoladas foram transferidas novamente para meios de cultura semi-sólido, e posteriormente, procedendo-se a verificação do crescimento, indicado pela formação de película característica. Todos os isolados foram então riscados no meio de cultura batata (Dobereiner et. al., 1995) e agrupados segundo os seguintes valores de características das colônias: 1ㅇvolor (reação): 1 = ácida, 2 = alcali.2ㅇvolor (forma): 1 = esférica, 2 = não esférica. 3 ㅇv valor (borda): 1 = lisa, 2 = crespa.

\section{RESULTADOS E DISCUSSÃO}

As maiores densidades de microorganismos diazotróficos endofíticos foram obtidos nos distintos nichos radiculares, e nas diferentes gramíneas forrageiras (Tabela 1), as quais são consideradas plantas hospedeiras comuns destas bactérias (Baldani et al., 1999).

Nas amostragens superficiais das raizes do capim Buffel registraram-se as maiores densidades populacionais de bactérias $\left(24 \times 10^{3}\right.$ bactérias $\mathrm{g}^{-1}$ de raiz fresca) em ralação as demais forrageiras, enquanto amostras do interior do capim Andropogon registraram as maiores densidades ( $46 \times 10^{3} \mathrm{~g}^{-1}$ bactérias de raiz fresca) entre as gramíneas.

Os valores máximos obtidos nos diferentes nichos (superfície e interior das raízes), apesar desta densidade estar diretamente relacionadas com a espécie vegetal associada (Baldani et al., 1999), estes valores podem ser considerados baixos, quando comparados aos encontrados para Azospirillum spp, por Dobereiner et al. (1995) $\left(10^{5}\right.$ e $10^{6}$ bactérias $\left.\mathrm{g}^{-1}\right)$, em raízes e solos de outras gramíneas, como milho e sorgo no Sudeste.

Resultados semelhantes foram verificados em raízes não lavadas de pupunha e braquiária na Amazônia ( $10^{5}$ bactérias $\mathrm{g}^{-1}$ de solo) por Magalhães \& Dobereiner(1984), como dentro da faixa de resultados obtidos em raizes desinfectadas superficialmente e na rizosfera de espécies de braquiárias em Goiás e Minas Gerais $\left(10^{3}\right.$ a $10^{7}$ bactérias $\left.\mathrm{g}^{-1}\right)$ por Reis Jr. et al. (2000). 
Tabela 1. Densidade de microorganismos diazotróficos endofítios nos diferentes nichos nas raízes de gramíneas forrageiras, avaliados em meio de cultura NFb (para Azospirillumspp.).

\begin{tabular}{|c|c|c|c|c|}
\hline \multirow[t]{2}{*}{ Gramíneas forrageiras } & \multicolumn{4}{|c|}{ Densidade de microorganismos } \\
\hline & \multicolumn{2}{|c|}{ Superfície da raiz } & \multicolumn{2}{|c|}{ Interior da raiz } \\
\hline & \multicolumn{4}{|c|}{$\left(\mathrm{NMP} \times 10^{3}\right)$ bactérias $\mathrm{g}^{-1}$ de raiz } \\
\hline & & $\begin{array}{l}\text { Limites de } \\
\text { confiança* }\end{array}$ & & $\begin{array}{l}\text { Limites de } \\
\text { confiança* }\end{array}$ \\
\hline Andropogon & 0,23 & $0,07-8,00$ & 46,00 & $10,00-210,00$ \\
\hline Tanzânia & 2,30 & $0,66-8,10$ & 0,11 & $0,03-0,42$ \\
\hline Buffel & 24,00 & $6,70-85,00$ & 6,40 & $1,50-28,00$ \\
\hline
\end{tabular}

* $95 \%$ de Probabilidade

O número total de isolados por nichos radiculares (superfície e interior das raízes) encontra-se no tabela 2 e figura 1. Foram obtidos isolados de diazotróficas, utilizando o meio de cultura NFb (para Azospirilum spp.) em todas as gramíneas e nichos radiculares, não havendo diferenças entre os mesmos.

Assim como observado para a densidade de microrganismos endofíticos no interior das raizes o capim Andropogon, obteve-se maior número de isolados em relação aos demais.

O número de fenótipos em relação ao número total de isolados não variou entre as formas de obtenção (na superfície e no interior das raízes), figura 1, indicando estabilidade com relação à riqueza fenotípica desses grupos de bactérias nos diferentes nichosradiculares.

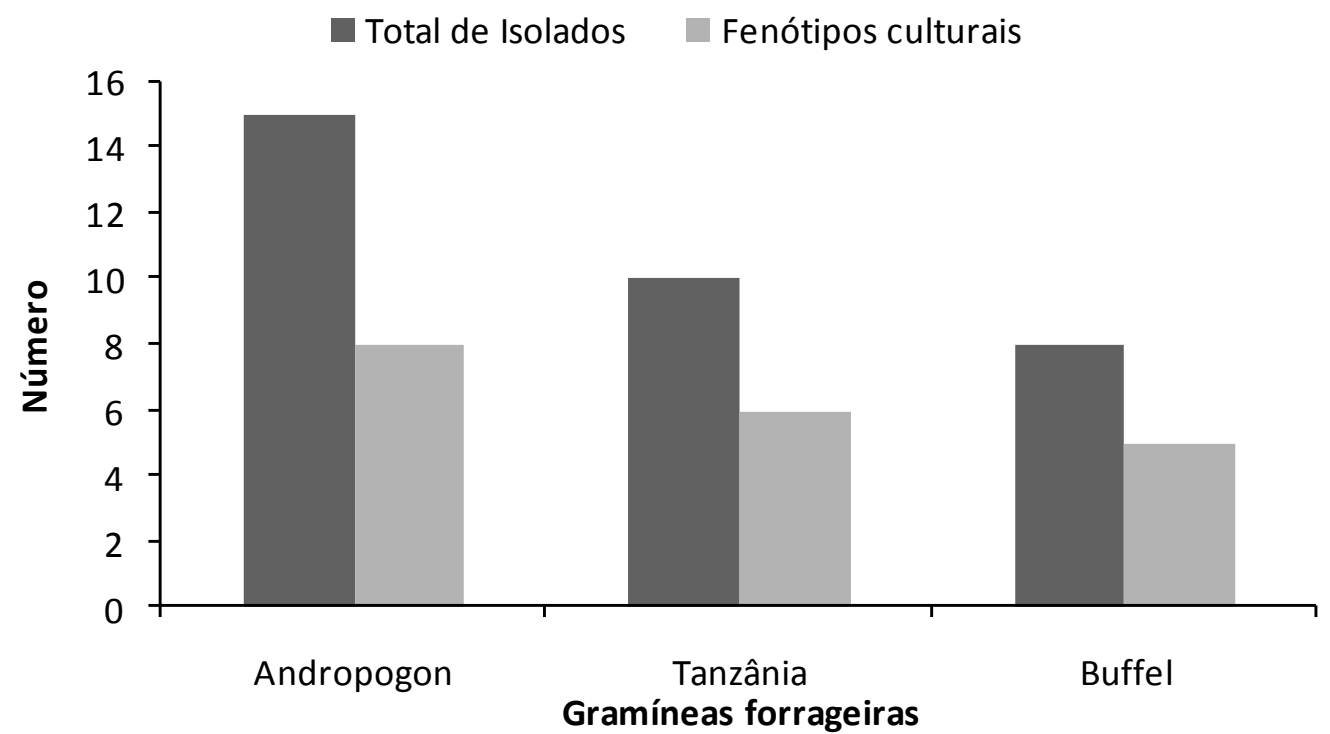

Figura 1 - Número de total de isolados e de fenótipos culturais correspondentes às gramíneas forrageiras coletadas. 
Tabela 2: Número isolados de diazotróficos endófitos por gramínea forrageira obtidas nos diferentes nichos em raizes frescas, utilizando o meio de cultura NFb (para Azospirillumspp.).

\begin{tabular}{lccc}
\hline \multirow{2}{*}{ Gramíneas forrageiras } & \multicolumn{2}{c}{ Número de isolados } & Total \\
\cline { 2 - 3 } \cline { 2 - 3 } Andropogon & Superfície da raiz & Interior da raiz & 15 \\
Tanzânia & 6 & 9 & 10 \\
Buffel & 6 & 4 & 8 \\
Total & 6 & 2 & 33 \\
\hline
\end{tabular}

Obteve-se isolados em todas as espécies de gramíneas e diferentes nichos radiculares, sendoobservada pequena diversidade fenotípica. Assim como observado para densidade de endófitos culturais, sendo encontrado quatro fenótipos (Tabela 3), onde os indivíduos dos grupos I, II, III e IV apresentaram dois, nove, doze e dez fenótipos respectivamente, apresentando similaridades entre si.

Apesar dos métodos moleculares serem considerados essenciais para identificação destas bactérias (Kirchof et al., 1997), estes resultados indicam que características culturais são também aplicáveis em estudos exploratórios da diversidade destas bactérias em diferentes ambientes (Melloni et al., 2004).

Tabela 3: Descrição das características dos fenótipos culturais com os respectivos isolados de bactérias diazotróficas endofíticas, obtidas em diferentes nichos de raizes frescas das gramíneas forrageiras.

\begin{tabular}{|c|c|l|}
\hline Fenótipo cultural & \multicolumn{1}{|c|}{ Descrição $^{(1)}$} & \multicolumn{1}{|c|}{ Isolados (Prefixo UFCG) } \\
\hline I & $1-1-1$ & 13,16 \\
\hline II & $1-2-1$ & $8,9,12,22,23,30,31,32,33$ \\
\hline III & $2-1-1$ & $1,2,3,6,7,17,18,19,20,21,26,27$ \\
\hline IV & $2-2-1$ & $4,5,10,11,14,15,24,25,28,29$, \\
\hline
\end{tabular}

(1) Descrição: 1 o valor (reação): 1 = ácida, 2 = alcali.2ㅇvolor (forma da colônia): 1 = esférica, 2= não esférica. 3ำ valor (borda da colônia): 1 = lisa, $2=$ crespa.

\section{CONCLUSÕES}

Diante dos resultados obtidos nesta pesquisa experimental, concluiu-se que:

- A densidade de bactérias diazotróficas endofíticas foi influenciada pelos nichos radiculares e gramíneas forrageiras;

- Os capim Andropogon e Buffel apresentaram maiores densidades de microrganismos diazotróficos endofíticos por grama de raiz fresca em nichos radiculares diferentes;

- Os microrganismos isolados apresentaram baixa diversidade fenótipica. 


\section{AGRADECIMENTOS}

Ao CNPq pela bolsa de Iniciação Científica.

\section{REFERÊNCIAS BIBLIOGRÁFICAS}

1. BALDANI, J.L.; AZEVEDO, M.S.; REIS, V.M.; TEXEIRA, K.R.S.; OLIVARES, F.L.; GOIS, S.R.; BALDANI, V.L.D.; DÖBEREINER, J. Fixação biológica de nitrogênio em gramíneas: avanços e aplicações. In: SIQUEIRA, J.O.; MOREIRA, F.M.S.; LOPES, A.S.; CARVALHO, J.G. eds. Interrelações fertilidade, biologia e nutrição de plantas. Viçosa, SBCS/UFLA/DCS, 1999. p. 621666.

2. BALDANI, V.L.D.; OLIVEIRA, E.; BOLOTA, E.; BALDANI, J.L.; KIRCHHOF, G.; DÖBEREINER, J. Burkhorderia brasiliensissp. nov., uma nova espécie de bactéria diazotrófica endofítica. Anais da Academia Brasileira de Ciência. v. 69, p. 116. 1997.

3. BASHAN, Y.; HOLGUIN, G. Azospirillum-plant relationships envoiomental and physiological advances (1990-1996). Canadian Journal Microbiology. v. 43, p. 103-121, 1997.

4. BAZZICALUPO, M.; OKON, Y. Associative and endophytic symbiosis. In: PEDROSA, F.; HUNGRIA, M.; YATES, M.G.; NEWTON, W.E., eds. Nitrogen Fixation: from moleculaes to crop productivity. Dordrecht, Kluwer Academic Publishers, 2000. p. 409-413.

5. DÖBEREINER J.; BALDANI, V.L.D. e BALDANI, J.I. Como isolar e identificar bactérias iazotróficas de plantas não leguminosas. Brasília, Empresa Brasileira de Pesquisa Agropecuária - CNPAB, 1995, 60 p.

6. DÖBEREINER J. Recent changes in concepts of plant bacteria interaction: endophytic $\mathrm{N}_{2}$ fixing bacteria. Ciência e Cultura - SBPC, v, 44, p. 310-313, 1992

7. EMBRAPA. Sistema Brasileiro de Classificação de Solos. Brasília: Brasília Produção de Informação, Rio de Janeiro, Embrapa Solos, 1999.

8. FARIA, S.M. Obtenção de estirpes de rizóbio eficientes na fixação de nitrogênio para espécies florestais. Seropédica: Embrapa Agrobiologia, Jan. 2002. 16p. (Embrapa-CNPAB. Documentos, 134).

9. FRANCO, A.A.; CAMPELLO, E.F.; SILVA, E.M.R. da; FARIA, S.M. de. Revegetação de solos degradados. Seropédica: EMBRAPA-CNPBS, 1992. 11p.(EMBRAPA CNPBS. Comunicado Técnico, 9).

10. KIRCHHOF, G.; SCHLOTER. M.; ABMUS, B; HARTMNN, A. Molecular microbial eclogy approaches applied to diazotrops associated whit non-legumes. Soil and Biological Biochemistry. v.29,p.853-862, 1997.

11. MAGALHÃES, F.M.M.; DÖBEREINER, J. Ocorrência de Azospirillum amazonense em alguns ecosistemas da Amazônia. Revista Microbiologia., v. 15, p. 246-252, 1984.

12. MELLONI, R., NÓBRAGA, R.S.A., MOREIRA, F.M.S., SIQUEIRA, J.O. Densidade e diversidade fenotípica de bactérias diazotróficas endofíticas em solos de mineração de bauxita, em reabilitação. Revista Brasileira de Ciência do Solo, v.28, p. 85-93, 2004.

13. ODUM, E.P. Ecologia. Editora Guanabara S.A. Rio de Janeiro, 1988, 434p. 
14. REIS Jr., F.B.; SANTOS, S.R.; TEXEIRA, K.R.S.; REIS,V.M.; DÖBEREINER, J. $\mathrm{N}_{2}$ - fixing bactéria associated with Bacchiaria pastures. In: PEDROSA, F.; HUNGRIA, M.; YATES, M.G.; NEWTON, W.E., eds. Nitrogen Fixation: from molecules to crop productivity. Dordrecht, Kluwer Academic Publishers, 2000. p. 432. 